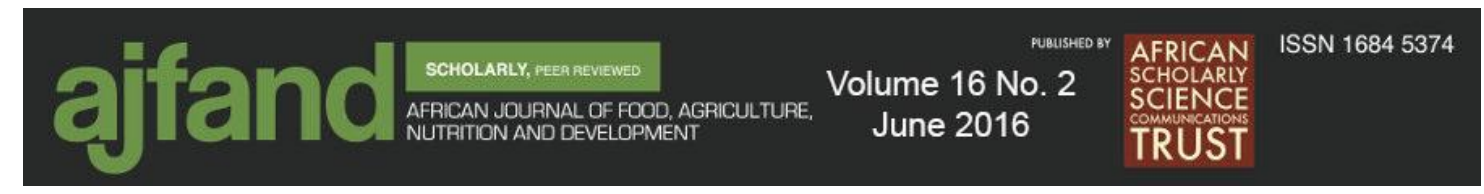

DOI: 10.18697/ajfand.74.15730

\title{
THE ASSOCIATION OF DEMOGRAPHIC VARIABLES AND DIETARY HABITS ON BODY MASS INDEX OF FOREIGN-BORN POPULATION IN SOUTH KOREA
}

\section{Obiang-Obounou BW'** and NB Ebrahim²}

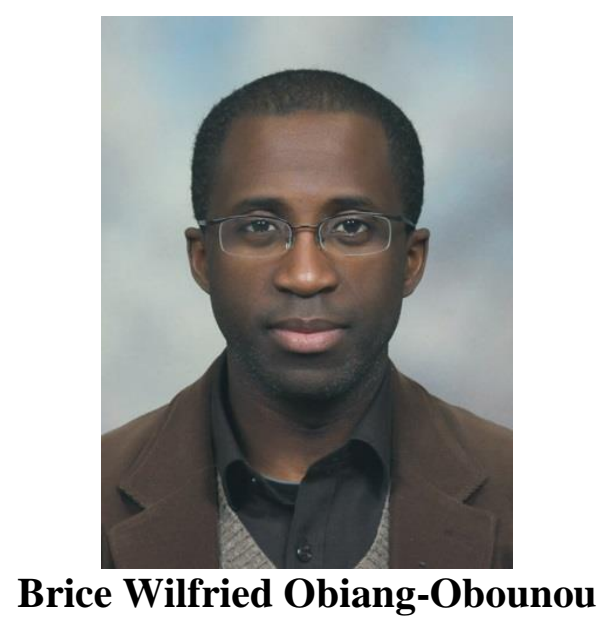

*Corresponding author email: obiang@gw.kmu.ac.kr

${ }^{1}$ Department of Food Science and Nutrition, Keimyung University, 1095, DalgubeolDaero, Dalseo-Gu, Daegu 704-701, Korea

${ }^{2}$ Department of Public health, Keimyung University, Daegu, Korea 


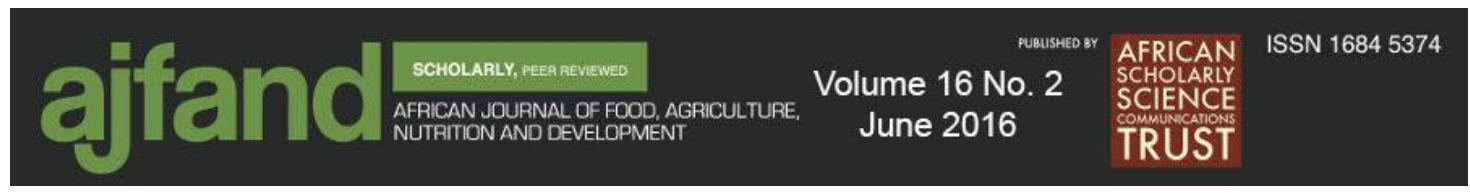

\begin{abstract}
The Republic of Korea (Korea) has been composed of a single ethnic group and, until very recently, has had little or no experience with large-volume of immigrants. The country, once known for its large-scale emigration, has emerged as a popular destination. As the foreign-born populations continue to grow, they experience dietary pattern changes. Dietary changes of immigrants are often associated with weight increase and consequently the risk of non-communicable diseases such as diabetes. This study examined the association of demographic variables and dietary habits on Body Mass Index (BMI) of foreign nationals living in Korea, based on a cross-sectional sample of 193 foreign-born men (120) and women (73). A web-based survey program, Zoho survey, was used to capture self-reported region of origin, socio-demographic variables, weight, height, frequency of physical activity, and food frequencies. For the entire sample ( $\mathrm{n}=193)$, the World Health Organization (WHO) classification and the Korean Society for the Study of Obesity cut-off points of BMI were used. The average BMI was $24.6(\mathrm{SD}=3.6) \mathrm{kg} / \mathrm{m}^{2}$. Significant associations were observed between BMI and age $\left(\chi^{2}\right.$ $(8, \mathrm{~N}=193)=26.22, \mathrm{p}<.01)$, gender $\left(\chi^{2}(2, \mathrm{~N}=193)=11.45, \mathrm{p}<.01\right)$, and religious affiliation $\left(\chi^{2}(4, \mathrm{~N}=191)=9.53, \mathrm{p}<.05\right)$. On average, participants had meat and carbonated drinks 2.2 times a week; high calorie foods 1.5 times a week; and, dairy products 2.4 times a week. A significant correlation $(r=.14, p<.05)$ between BMI and eating meat was also observed. This study showed that the BMI varied with age, gender and religion. Frequent consumption of meat was associated with a significant increase in BMI. This increase in BMI could be associated with the dietary changes experienced by the newcomers or absence of more familiar products. Consequently, as the volume of immigrants continues to increase in Korea, it is imperative to consider designing and implementing public health policies specifically in relation to a healthy diet that can impact the prevalence of preventable chronic diseases. Thus, health education among foreign-born population in Korea should focus on reducing the intake of meat and high energy foods.
\end{abstract}

Key words: Acculturation, BMI, Demographic, Dietary habits, Korea, Immigrants, Physical Activity 


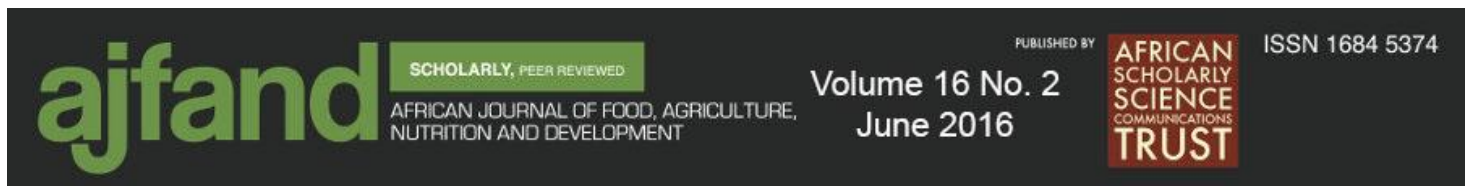

\section{INTRODUCTION}

The Republic of Korea which used to be a migrant source country sending workers mainly to the United States (U.S), Germany and the Middle East, is now a receiving country of foreign nationals. Contrary to Europe where immigrant groups represent between $9 \%$ (United Kingdom) and 15\% (Austria) of the total population [1], the number of registered foreigners $(932,983$ as of 2012) in Korea accounts for only 1\%. However, as this population continues to grow and experience acculturation, it is imperative to consider them when designing and implementing public health policies specifically in relation to a healthy diet that can impact the prevalence of preventable chronic diseases. Acculturation is the process of cultural change of behaviors of another group [2]; usually in the direction of a minority group adopting habits of the dominant group. Food habits and food consumption changes are some of the new behaviors affected by acculturation. It is well understood that migration influences dietary patterns of immigrant groups [3] because of the changes in their eating habits encountered in the host countries. These changes are often associated with a higher Body Mass Index (BMI) or obesity [4]. In addition, reports associate other variables such as socio-demographic factors to obesity [5]. Furthermore, the rapid economic growth of Korea forced the country away from its traditional diets of mainly vegetables and grains to less healthy and readily-available processed foods that are available to the immigrants as well. As far as known to these researchers, the present study is the first to examine the association between BMI, physical activity and dietary habits of foreign-born population in the Republic of Korea.

The World Health Organization (WHO) has recommended classifications of bodyweight that include degrees of underweight, normal weight, excess weight or overweight that are associated with the increased risk of non-communicable chronic diseases $[6,7]$. The WHO classifications are based on body-mass index (BMI), which is a measure of a person's thickness or thinness based on an individual's mass and height. It is calculated as weight in kilograms divided by height in meters squared $\left(\mathrm{kg} / \mathrm{m}^{2}\right)$ and has been directly linked to increased risk of morbidity and mortality in many populations. Higher BMI is reported to be associated with greater risk for certain non-communicable diseases (NCDs), specifically cardiovascular diseases, cancers, diabetes and chronic lung diseases [8] and is reported to be responsible for over 36 million deaths annually worldwide [8, 9]. While these conditions are non-infectious and chronic in nature, they are, nonetheless caused to a large extent, by four modifiable behavioral risk factors that are pervasive aspects of the economic transition, rapid urbanization, and 21st-century lifestyles. These include tobacco use, unhealthy diet, insufficient physical activity, and the harmful use of alcohol. For instance, some studies have shown that dietary factors alone account for about $30 \%$ of the cancers [10]. The purpose of the study was, therefore, to investigate and describe the association between BMI, dietary habits and physical activity among the foreign-born population living in the Republic of Korea.

\section{MATERIALS AND METHODS}

\section{Participants}

Participants were a cross-sectional sample of 193 foreign-born men (120) and women (73). The main recruiting criteria were being a foreigner and currently residing in South 


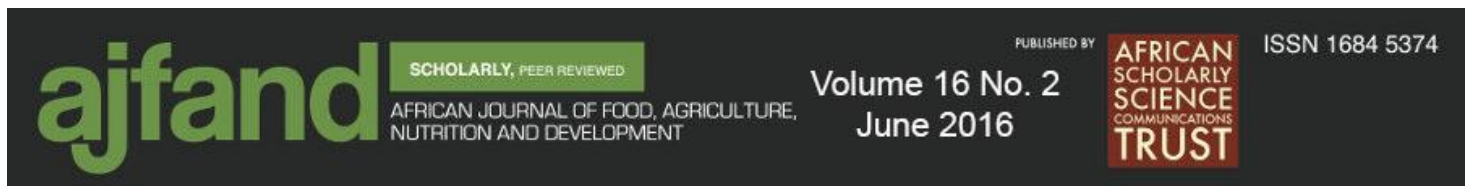

Korea. A written consent prompt was provided such that only those who were willing to participate in the study could proceed. The study was anonymous and followed the ethical standards stipulated in the Helsinki Declaration as none of the personally identifiable information such as name, social security number, date of birth, phone numbers, and so forth was captured. A web-based survey program, Zoho survey, was used to collect the data from December 2013 to January 2014 during which time participants self-reported demographic variables such as age, gender, occupation, education, and country of origin (later classified into regions) along with their weight, height, frequency of physical activity, and food frequency information.

\section{Self-Reported Measurement}

Anthropometric variables, which included body weight and height, were used to calculate body mass index (BMI). For the entire sample $(n=193)$, the WHO's BMI classification for adults and cut-off points $<18.5 \mathrm{~kg} / \mathrm{m}^{2}$ for underweight, $18.5-24.9 \mathrm{~kg} / \mathrm{m}^{2}$ for normal weight, $25.0-29.9 \mathrm{~kg} / \mathrm{m}^{2}$ for overweight and $\geq 30 \mathrm{~kg} / \mathrm{m}^{2}$ for obesity were used[7]. The latter two were combined during analysis because only $11(5.7 \%)$ participants fell under the obese category. For the Asian sub-sample $(n=42)$ the researchers used the Korean Society for the Study of Obesity (KSSO) cut-off points of BMI underweight $\leq 18.5 \mathrm{~kg} / \mathrm{m}^{2}$, normal weight $18.5-23.0 \mathrm{~kg} / \mathrm{m}^{2}$, overweight $23.0-24.9 \mathrm{~kg} / \mathrm{m}^{2}$, and obese $\geq 25.0 \mathrm{~kg} / \mathrm{m}^{2}$. Studies suggested that Asian populations have different associations between BMI, percentage of body fat, and health risks than do European populations. Consequently, the proportion of Asian people with a high risk of type 2 diabetes and cardiovascular disease is substantial at BMIs lower than the existing WHO cut-off point for overweight $(<25$ $\left.\mathrm{kg} / \mathrm{m}^{2}\right)[11,12]$. Physical activity was measured by the frequency of moderate or heavy exercise per week. The dietary habits of the participants were assessed from the food frequency information by factor analysis that identified three dietary habits, namely meat, high calorie, and dairy.

\section{Human subjects research approval}

This study was approved by the Institutional Review Board (IRB) of Keimyung University (IRB file number: 40525-201410-HR-71-02). Since the study interviewed healthy people and participants could not be identified after the interview, informed consent form requirements were waived. However, before the participants answered the questionnaire, they received information from the researcher about the survey, including its purpose, procedures, and confidentiality.

\section{Data analysis}

After subject identification numbers were assigned to each questionnaire, data were analyzed by statistical software SPSS 21.0 database. Frequency distribution table was generated for each variable. For parametric variables, the assumption of normality was assessed by skewness, kurtosis, box plots, and histograms. Variables that were not normally distributed were subjected to square root transformation. Three univariate outliers in the BMI variable were replaced with the next highest value [10]. In the data set, $35(18 \%)$ of values on physical activity were missing. Large missing data can affect statistical power and introduce bias in parameter estimate [13-15]. Hence, hot deck technique was used to impute the missing data [14]. 


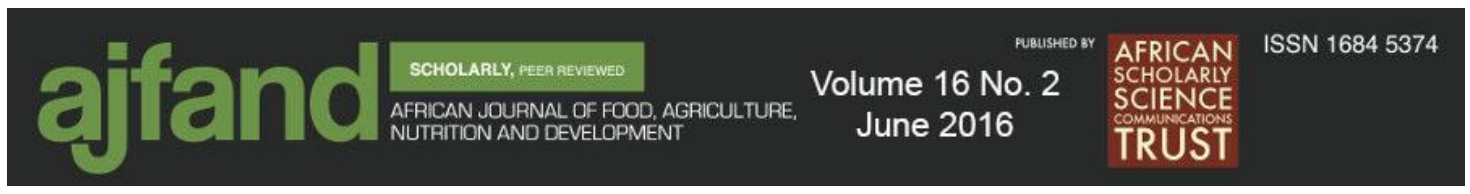

All variables on the food frequency questions were loaded onto an exploratory factor analysis. To estimate factors, a maximum likelihood procedure was used, and factor structure rotated by direct oblimin method. The number of factors retained was determined by the scree test [13]. Items with loadings below 0.4 and those cross-loaded on different factors were dropped. The result of the exploratory factor analysis of the food frequency identified three dietary patterns: meat (beef, chicken, and pork), high calorie (pasta, corn, French fries, fried fish, and ice cream), and dairy (milk, cheese, and yogurt). Frequency values on these food items were added and averaged to obtain an overall score for each dietary pattern and used in further analysis.

Descriptive statistics (percentages, means, and standard deviations) were calculated to describe the characteristics of the study population. Bivariate associations for nonparametric variables were examined by chi-square analyses. Pearson's correlations were computed to show the predictive relationships between different variables. A p-value less 0.05 was used to determine the statistical significance and all the analyses were two-tail tests.

\section{RESULTS}

\section{Sample characteristics}

A summary of the participants' anthropometric characteristics are illustrated in Table 1. The sample consisted of 193 foreigners in South Korea of whom 120 (62\%) were men, and $73(38 \%)$ were women. The anthropometric characteristics of the participants reveals a relatively healthy population with an average BMI of $24.6(\mathrm{SD}=3.6) \mathrm{kg} / \mathrm{m}^{2}$ for men and $23.6(\mathrm{SD}=4.1) \mathrm{kg} / \mathrm{m}^{2}$ for women. However, half of the men $60(50 \%)$ were classified as either overweight or obese. Among women 25 (34.2\%) were classified as overweight or obese. It is interesting to note that the majority of women had healthy body weight; however, overall, 5 (2.5\%) of the participants were classified as underweight and were all women accounting for $7 \%$ of the women population. Of the 193 study participants, $11(5.7 \%)$ were classified as obese, with $6(3.1 \%)$ men and $5(2.5 \%)$ women.

\section{Body mass index by demographic variables}

Table 2 shows the results of BMI by demographic variables of the participants. The overall average $\mathrm{BMI}$ was $24.6(\mathrm{SD}=3.6)$ and the range was $17.0-40.1$. The majority of the participants $(78 \%)$ were between 18 and 31 years of age, and $66 \%$ were Christian, 9\% Muslims, and $25 \%$ had different faiths. Participants were from different regions of the world: Americas 34 (18\%), Europe 36 (19\%), Africa 79 (41\%), and Asia 42 (22\%). The vast majority, $151(80 \%)$, had college degrees, and $136(72 \%)$ were college students at higher learning institutions in South Korea. There was a significant association between the age of the participants and their BMI. The proportion of participants who had a normal BMI decreased as their age increased. Conversely, the proportion of participants who were overweight or obese increased with their age $\left(\chi^{2}(8, N=193)\right.$ $=26.22, \mathrm{p}<.01)$. Gender and BMI also showed a significant association $\left(\chi^{2}(2, \mathrm{~N}=193)\right.$ $=11.45, \mathrm{p}<.01)$. While more women had a normal BMI than men $(59 \%$ versus $50 \%)$, men were twice more likely to be overweight or obese than women. Religious affiliations of the study participants were also significantly associated with $\mathrm{BMI}\left(\chi^{2}(4, \mathrm{~N}=191)=9.53\right.$, 


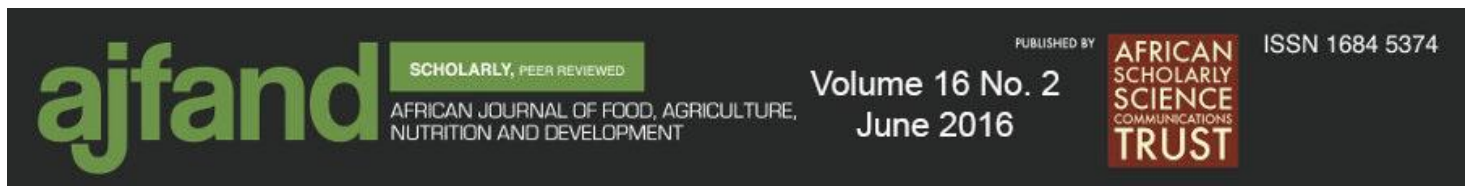

$\mathrm{p}<.05)$. Participants who identified themselves as Christians or Muslims appeared to have a larger proportion of overweight or obese individuals as compared to individuals with different religious affiliations, or atheists. Similarly, participants' employment was also significantly associated with BMI $\left(\chi^{2}(4,190)=16.24, p<.01\right)$. However, participants' region of origin and their level of education were not significantly associated with their BMI.

\section{Asian BMI}

Table 3 shows the average BMI for a sub-sample $(n=42)$ of Asian men and women as $24.9 \mathrm{~kg} / \mathrm{m}^{2}$ and $22.1 \mathrm{~kg} / \mathrm{m}^{2}$, respectively. However, according to the new classification for BMI cut-off points (BMI>23 kg/m² considered overweight) [12], 57.9\% of Asian males and $54.4 \%$ of Asian females fell under the overweight or obese category. The results show that the WHO BMI cut-off points in fact underestimates obesity-related risks in these populations.

\section{BMI, physical activity, and eating habits}

On average, physical activity measured as self-reported weekly frequency of moderate to heavy activity was twice a week (Table 4). Thirty-four percent (34\%) of the participants did not perform any form of physical activity during the week, $40 \%$ exercised 1-2 times a week, 17\% exercised 3-4 times a week, and 7.5\% exercised over 5 times a week (results not shown here). The dietary habits of participants derived from food frequency questions showed that participants had meat and carbonated drinks, 2.2 times a week, high calorie foods, 1.5 times a week, and dairy products, 2.4 times a week (Table 4). A small but positive and significant correlation $(r=0.14, p<.05)$ between BMI and meat consumption was observed. Interestingly, frequent meat consumption was positively and significantly correlated with eating high calorie diets $(r=0.15, \mathrm{p}<.05)$. Other variables were not significantly correlated.

\section{DISCUSSION}

Although BMI has its limitations when it comes to estimating body fat in athletes and other muscularly built individuals where BMI value is overestimated, high BMI has been identified as a risk factor for certain chronic diseases. The new classification of Asian BMI (Table 2) shows that 55\% $(n=22 / 40)$ are either overweight or obese. The results confirmed the study published by Wang and colleagues [16] and the WHO expert consultation [6], that Asians had lower body mass index but had higher percent of body fat than other races based on anthropometric measurements. Thus, the proportion of Asian people with risk factor for type 2 diabetes and cardiovascular disease could be substantial even when individuals fall below the existing WHO BMI cut-off point of 25 $\mathrm{kg} / \mathrm{m}^{2}$.

South Korea has experienced rapid and varied socio-economic changes since hosting the 1988 Olympic Games [17, 18]. One of the changes related to the rapid economic development is increased consumption of animal products and reduction of plant-based foods. Through time, people who move to a new country tend to adopt the lifestyle including dietary habits of the host nation. Among the study participants, increased consumption of meat products as shown in Table 4 was associated with a higher BMI. 


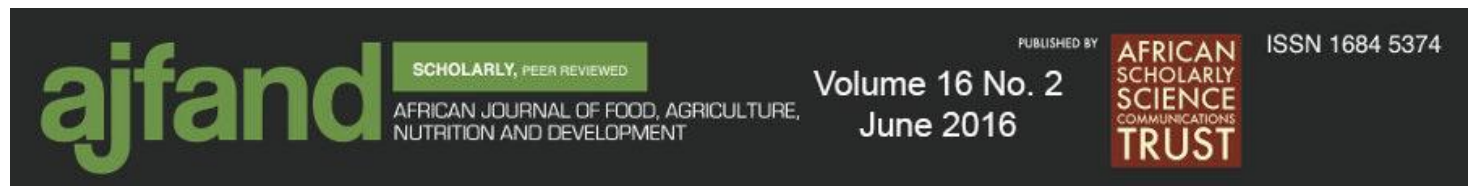

The results are in agreement with Spencer and colleagues who observed that high protein and low fiber intake were the factors most strongly associated with increased BMI [19]. The need of the South Koreans to conform to the Western diet by shifting from the traditional diet comes with an increased risk for various chronic conditions such as cardiovascular diseases, cancers, diabetes, and chronic lung diseases.

As for the reasons why some foreigners were not engaging in physical activities, busy schedule $(79 \%)$, dislike exercise $(7 \%)$ or extra burden $(2 \%)$ were mentioned. Regardless of age, ethnicity, or present state of health, all individuals can benefit from regular, moderate physical activity as it is associated with a decreased risk of heart disease, obesity, hyperlipidemia, vascular disease, and type 2 diabetes [20]. However, Rauner et al. [21] stated in their review that the relationship between physical activity and BMI is not often clear as the definitions and measurement instruments (questionnaire, accelerometer, and activity monitor) are different from one study to another. Their assessment was confirmed by different authors who detected a relationship between objectively measured physical activity and overweight [22], and others who did not find any relationship between overweight and objectively measured physical activity $[23,24]$.

Data from this research are self-reported physical activity and there is a potential for over or underestimation [22]. The lack of direct correlation between physical activity and BMI in this study may be that the higher BMI observed in this study is not dependent on physical activity but on dietary pattern, as an increased meat consumption (2.2/week) and high calorie foods (1.5/week) were significantly correlated with BMI (Table 4). Moreover, the present study shows that people who frequently eat meat tend to also like high calorie foods such as fries, fried fish or ice cream.

The anthropometric characteristics suggest that participants had healthy BMI. However, it showed marked variations in age, gender, religion, and occupation in relation to their BMI. Frequent meat consumption was significantly related to the BMI and eating high energy diet. It is suggested that health education among the foreign-born population in Korea should focus on promoting healthy diet (reduced intake of meat and high energy foods) and increased physical activity. Moreover, it is important to focus on work-life balance that promotes a healthy lifestyle.

\section{Limitations of the study}

There were some limitations to this study. The study was cross-sectional, thus conclusions could not be made about causal relationships. Since participants were not randomly selected but volunteered to participate, the external validity and generalizability of the results may be limited to the study population. In addition, participants self-reported their anthropometric values, and diet and lifestyle experiences, which may be a potential for over or underestimation.

\section{CONCLUSION}

The study showed that the BMI varied with age, gender, and religion. Frequent consumption of meat was associated with a significant increase in BMI. No association was found with carbonated drinks, milk and cheese. This increase in BMI could be 


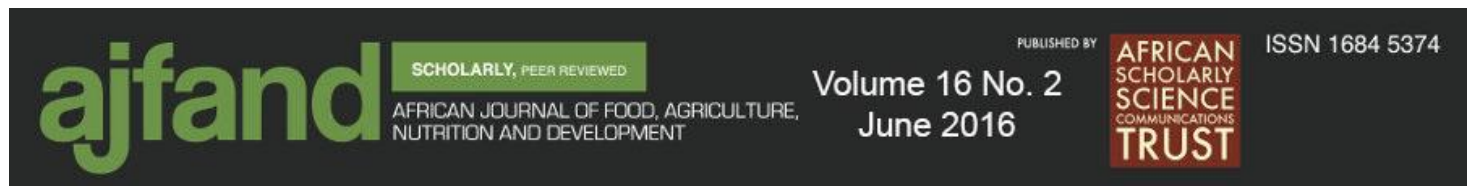

associated with the dietary changes experienced by the newcomers or absence of more familiar products. Health education among foreign-born population in Korea should focus on reducing the intake of meat and high energy foods. 


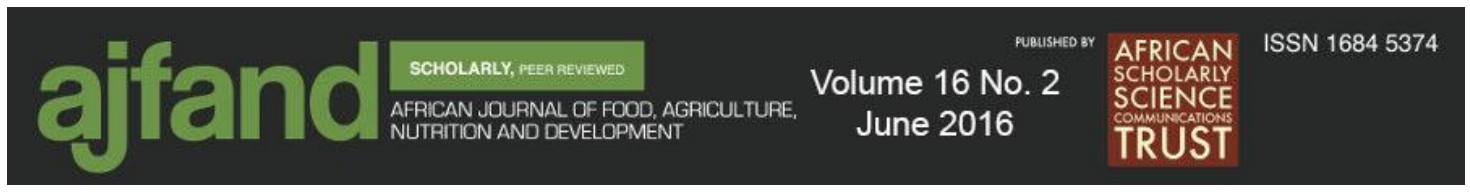

Table 1: Anthropometric characteristics (mean value) of the participants

\begin{tabular}{lll}
\hline & Male $(\mathbf{n}=120)$ & Female $(\mathbf{n}=73)$ \\
\hline Height $(\mathrm{cm})$ & $173.5 \pm 7.0(147-190)$ & $164.2 \pm 6.6(150-189)$ \\
Weight $(\mathrm{kg})$ & $74.1 \pm 12.0(45-120)$ & $63.6 \pm 11.2(47-120)$ \\
BMI $\left(\mathrm{kg} / \mathrm{m}^{2}\right)$ & $24.61 \pm 3.6(17.58-39.08)$ & $23.57 \pm 4.1(17.01-40.09)$ \\
Underweight $(\%)$ & $0(0.0)$ & $5(6.8)$ \\
Normal $(\%)$ & $60(50.0)$ & $43(58.9)$ \\
Overweight \& obese $(\%)$ & $60(50.0)$ & $25(34.2)$ \\
\hline
\end{tabular}




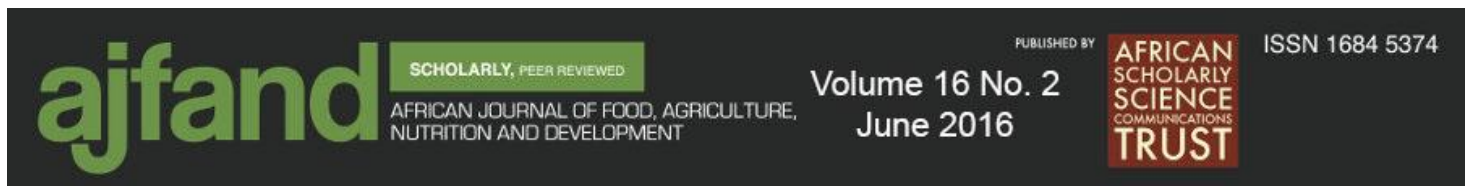

Table 2: Body Mass Index (BMI) by demographic variables

\begin{tabular}{|c|c|c|c|c|c|}
\hline \multirow[t]{2}{*}{ Variables } & \multicolumn{4}{|c|}{$\mathrm{BMI}\left(\mathrm{kg} / \mathrm{m}^{2}\right)$} & \multirow{2}{*}{$\frac{\chi^{2}}{P}$} \\
\hline & $\begin{array}{l}<18.5 \\
\text { (underweight) }\end{array}$ & $\begin{array}{l}18.5-24.9 \\
\text { (normal) }\end{array}$ & $\begin{array}{l}25 \& \text { above } \\
\text { (overweight } \\
\& \text { obese) }\end{array}$ & Total & \\
\hline Age (years) & \multicolumn{4}{|c|}{$\mathrm{N}(\%)$} & \\
\hline $18-23$ & $1(2.3)$ & $33(76.7)$ & $9(20.9)$ & 43 (100.0) & \\
\hline $24-27$ & $3(4.6)$ & $35(53.8)$ & $27(41.5)$ & $65(100.0)$ & 26.22 \\
\hline $28-31$ & $0(0)$ & $21(50.0)$ & $21(50.0)$ & $42(100.0)$ & .002 \\
\hline $32-37$ & $0(0)$ & $10(47.6)$ & $11(52.4)$ & $21(100.0)$ & \\
\hline$\geq 38$ & $1(4.5)$ & $4(18.2)$ & $17(77.3)$ & $22(100.0)$ & \\
\hline \multicolumn{6}{|l|}{ Gender } \\
\hline Male & $0(0.0)$ & $60(50.0)$ & $60(50.0)$ & $120(100.0)$ & 11.45 \\
\hline Female & $5(6.8)$ & $43(58.9)$ & $25(34.2)$ & $73(100.0)$ & .003 \\
\hline \multicolumn{6}{|l|}{ Religion } \\
\hline Christian & $1(.8)$ & $69(54.8)$ & $56(44.4)$ & $126(100.0)$ & 9.53 \\
\hline Muslim & $2(11.8)$ & $6(35.3)$ & $9(52.9)$ & $17(100.0)$ & .049 \\
\hline Others & $2(4.2)$ & $28(58.3)$ & $18(37.5)$ & $48(100.0)$ & \\
\hline \multicolumn{6}{|l|}{ Region } \\
\hline Americas & $1(2.9)$ & $13(38.2)$ & $20(58.8)$ & $34(100.0)$ & 10.08 \\
\hline Europe & $2(5.6)$ & $22(61.1)$ & $12(33.3)$ & $36(100.0)$ & .121 \\
\hline Africa & $0(0)$ & $48(60.8)$ & $31(16.2)$ & $79(100.0)$ & \\
\hline Asia & $2(4.8)$ & $20(47.6)$ & $20(47.6)$ & $42(100.0)$ & \\
\hline \multicolumn{6}{|l|}{ Employment } \\
\hline Student & $4(2.9)$ & $84(61.8)$ & $48(35.3)$ & $136(100.0)$ & 16.24 \\
\hline Employed & $1(2.1)$ & $16(33.3)$ & $31(64.6)$ & $48(100.0)$ & .003 \\
\hline Unemployed & $0(0)$ & $1(16.7)$ & $5(83.3)$ & $6(100.0)$ & \\
\hline \multicolumn{6}{|l|}{ Education } \\
\hline High school & $0(0)$ & $5(71.4)$ & $2(28.6)$ & $7(100.0)$ & 2.74 \\
\hline Some college & $0(0)$ & $16(48.5)$ & $17(51.5)$ & $33(100.0)$ & .603 \\
\hline College degree & $5(3.3)$ & $81(53.6)$ & $65(43.0)$ & $151(100.0)$ & \\
\hline
\end{tabular}




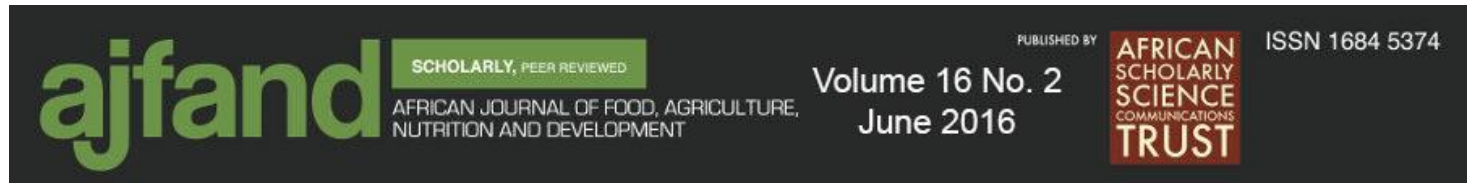

Table 3: Relationship between gender and BMI of Asian study participants $(n=42)$

\begin{tabular}{|c|c|c|c|c|c|}
\hline \multirow[t]{2}{*}{ Variable } & \multicolumn{4}{|c|}{$\mathrm{BMI}\left(\mathrm{kg} / \mathrm{m}^{2}\right)$} & $\chi^{2}$ \\
\hline & $\begin{array}{c}<18.5 \\
\text { (underweight) }\end{array}$ & $\begin{array}{c}18.5-22.99 \\
\text { (normal) }\end{array}$ & $\begin{array}{c}\geq 23 \\
\text { (over } \\
\text { weight \& } \\
\text { obese ) }\end{array}$ & Total & $\mathrm{p}$ \\
\hline Male & $1(5.0)$ & $8(40.0)$ & $11(55.0)$ & $20(100.0)$ & .127 \\
\hline Female & $1(4.5)$ & $10(45.5)$ & $11(50.0)$ & $22(100.0)$ & .938 \\
\hline
\end{tabular}

Table 4: BMI, dietary habit, and physical activity: correlations and descriptive statistics $(\mathrm{n}=193)$

\begin{tabular}{|c|c|c|c|c|c|}
\hline Variables & 1 & 2 & 3 & 4 & 5 \\
\hline 1. BMI & - & & & & \\
\hline 2. Meat ${ }^{1}$ & $.14^{*}$ & - & & & \\
\hline 3.Highcalorie ${ }^{2}$ & .06 & $.15^{*}$ & - & & \\
\hline 4. Dairy ${ }^{3}$ & .07 & .03 & .06 & - & \\
\hline 5.Physical activity & .10 & .07 & .06 & .130 & - \\
\hline Mean & 24.2 & 2.2 & 1.5 & 2.4 & 1.7 \\
\hline$S D$ & 3.8 & 1.1 & .78 & 1.45 & 1.7 \\
\hline
\end{tabular}




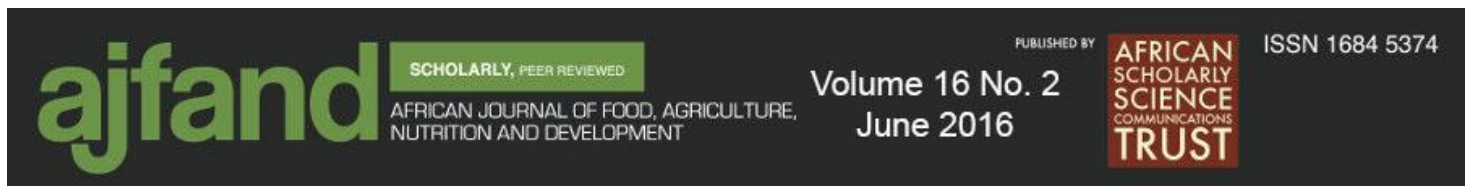

\section{REFERENCES}

1. Garduno-Diaz SD, Husain W, Ashkanani F and S Khokhar Meeting challenges related to the dietary assessment of ethnic minority populations. J Hum Nutr Diet. 2013; 4:358-366.

2. Obiang-Obounou B Dietary Acculturation of Foreign Students in Daegu, Korea. J. Hum Nutr Food Sci. 2015; 3(4):1068.

3. Kaiser $\mathbf{L}$ What can binational studies reveal about acculturation, food insecurity, and diet? J Am Diet Assoc. 2009; 109(12):1997-2000.

4. Shah SM, Loney T, Dhaheri SA, Vatanparast H, Elbarazi I, Agarwal M, Blair I and R Ali Association between acculturation, obesity and cardiovascular risk factors among male South Asian migrants in the United Arab Emirates -a cross-sectional study. BMC Public Health. 2015; 15:204.

5. Stewart-Knox B, Duffy EM, Bunting B, Parr H, Vas de Almeida MD and M Gibney Associations between obesity (BMI and waist circumference) and socio-demographic factors, physical activity, dietary habits, life events, resilience, mood, perceived stress and hopelessness in healthy older Europeans. BMC Public Health 2012; 12:424.

6. WHO. Expert Committee on Physical Status. Physical status : the use and interpretation of anthropometry. Report of a WHO Expert Committee. Geneva: World Health Organization. 1995.

7. World Health Organization. Obesity : preventing and managing the global epidemic. Geneva: World Health Organization. 2000.

8. World Health Organization. Global status report on non-communicable diseases 2010. Geneva, Switzerland: World Health Organization. 2011.

9. Chopra M, Galbraith S and I Darnton-Hill A global response to a global problem: the epidemic of overnutrition. Bull World Health Organ. 2002; 80(12):952-958.

10. Key TJ, Schatzkin A, Willett WC, Allen NE, Spencer EA and RC Travis Diet, nutrition and the prevention of cancer. Public Health Nutr. 2004; 7(1A):187-200.

11. Ko MS The comparison in daily intake of nutrients, dietary habits and body composition of female college students by body mass index. Nutr Res Pract. 2007; 1(2):131-142.

12. KSSO. The Asia-pacific perspective: Redefining obesity and its treatment. 2000. Seoul, Korea. 


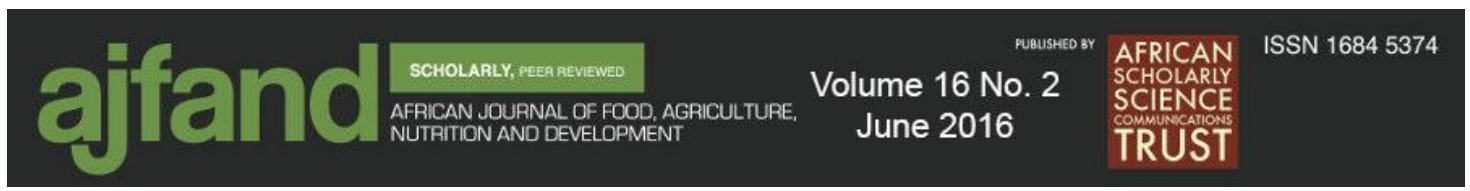

13. Acock AC Working With Missing Values. J. Marriage Fam. 2005; 67(4):10121028.

14. Myers TA Goodbye, Listwise Deletion: Presenting Hot Deck Imputation as an Easy and Effective Tool for Handling Missing Data. Commun Methods Meas. 2011; 5(4):297-310.

15. Tabachnick BG and LS Fidell Using Multivariate Statistics (5th Edition): Allyn ; Bacon, Inc.; 2006.

16. Wang J, Thornton JC, Russell M, Burastero S, Heymsfield S and RN Pierson Jr Asians have lower body mass index (BMI) but higher percent body fat than do whites: comparisons of anthropometric measurements. Am J Clin Nutr. 1994; 60(1):23-28.

17. Lee MJ, Popkin BM and S Kim The unique aspects of the nutrition transition in South Korea: the retention of healthful elements in their traditional diet. Public Health Nutr. 2002; 5(1A):197-203.

18. Sakamaki R, Amamoto R, Mochida Y, Shinfuku N and K Toyama A comparative study of food habits and body shape perception of university students in Japan and Korea. Nutr J. 2005; 4:31.

19. Spencer EA, Appleby PN, Davey GK and TJ Key Diet and body mass index in 38000 EPIC-Oxford meat-eaters, fish-eaters, vegetarians and vegans. Int $J$ Obes Relat Metab Disord . 2003; 27(6):728-734.

20. Kim J, Must A, Fitzmaurice GM, Gillman MW, Chomitz V, Kramer E, McGowan R and KE Peterson Relationship of physical fitness to prevalence and incidence of overweight among schoolchildren. Obes Res. 2005; 13(7):1246-1254.

21. Rauner A, Mess $\mathbf{F}$ and A Woll The relationship between physical activity, physical fitness and overweight in adolescents: a systematic review of studies published in or after 2000. BMC Pediatr. 2013; 13:19.

22. Lohman TG, Ring K, Pfeiffer K, Camhi S, Arredondo E, Pratt C, Pate R and LS Webber Relationships among fitness, body composition, and physical activity. Med Sci Sports Exerc. 2008, 40(6):1163-1170.

23. Aires L, Silva P, Silva G, Santos MP, Ribeiro JC and J Mota Intensity of physical activity, cardiorespiratory fitness, and body mass index in youth. $J$ Phys Act Health. 2010; 7(1):54-59.

24. Ng C, Marshall D and ND Willows Obesity, adiposity, physical fitness and activity levels in Cree children. Int J Circumpolar Health. 2006; 65(4):322-330. 